\title{
On Ti-18Si-6B and Ti-7.5Si-22.5B Powder Alloys Prepared by High-energy Ball Milling and Sintering
}

\author{
Bruno Bacci Fernandes ${ }^{\mathrm{a}, \mathrm{b} *}$, Alfeu Saraiva Ramos ${ }^{\mathrm{c}}$, Carlos de Moura Neto ${ }^{\mathrm{a}}$,
}

Gilberto Carvalho Coelho ${ }^{\text {d, Paulo Atsushi Suzuki }}{ }^{\mathrm{d}}$

\author{
anstituto Tecnológico de Aeronáutica - ITA, CEP 12228-900, São José dos Campos, SP, Brasil \\ ${ }^{\mathrm{b}}$ Instituto Nacional de Pesquisas Espaciais - INPE, CEP 12227-010, São José dos Campos, SP, Brasil \\ ${ }^{\mathrm{c}}$ Universidade Estadual Paulista - UNESP, CEP 12516-410, Guaratinguetá, SP, Brasil \\ ${ }^{\mathrm{d}}$ Universidade de São Paulo - USP, CEP 12600-000, Lorena, SP, Brasil
}

Received: January 5, 2012; Revised: June 22, 2012

\begin{abstract}
Recently, a new ternary phase was discovered in the Ti-Si-B system, located near the $\mathrm{Ti}_{6} \mathrm{Si}_{2} \mathrm{~B}$ composition. The present study concerns the preparation of titanium alloys that contain such phase mixed with $\alpha$-titanium and other intermetallic phases. High-purity powders were initially processed in a planetary ball-mill under argon atmosphere with Ti-18Si-6B and Ti-7.5Si-22.5B at. (\%) initial compositions. Variation of parameters such as rotary speed, time, and ball diameters were adopted. The as-milled powders were pressureless sintered and hot pressed. Both the as-milled and sintered materials were characterized by X-ray diffraction, scanning electron microscopy and energy-dispersive spectrometry. Sintered samples have presented equilibrium structures formed mainly by the $\alpha-\mathrm{Ti}+\mathrm{Ti}_{6} \mathrm{Si}_{2} \mathrm{~B}+\mathrm{Ti}_{5} \mathrm{Si}_{3}+\mathrm{TiB}$ phases. Silicon and boron peaks disappear throughout the milling processes, as observed in the powder diffraction data. Furthermore, an iron contamination of up to 10 at. (\%) is measured by X-ray spectroscopy analysis on some regions of the sintered samples. Density, hardness and tribological results for these two compositions are also presented here.
\end{abstract}

Keywords: multiphase intermetallics, phase identification, powder metallurgy

\section{Introduction}

Several medical and dental devices (e.g. surgical instruments, prostheses or orthodontic components) are manufactured from metallic materials. Bearing surfaces of hip prostheses require materials characterized by high wear and corrosion resistance. These characteristics need to be tailored to the peculiar conditions found on the human body as variable loading and corrosion levels. Co-Cr-Mo alloys feature high wear resistance and also provide a longer lifetime for such applications. Nevertheless, in vivo processes of degradation generate debris that release Co and $\mathrm{Cr}$ ions which in turn contribute to adverse biological reactions. Co-Cr-Mo alloys present structures formed by a metal with intermetallic phases ${ }^{1,2}$. Currently, there is no consensus on what constitutes an ideal material to be used as implants under the variable environment encountered on bones and tissues, as mentioned earlier. A recent study states that the Ti-10Si-5B alloy has good biocompatibility features ${ }^{3}$.

Ti-6Al-4V wt. (\%) alloys are employed on the fabrication of medical, aeronautical (e.g. gas turbine blades) and aerospace (e.g. gas bottle of satellite launcher vehicles) components, which must support harsh conditions under different temperatures ${ }^{4}$. Multiphase alloys have been considered as the best option for structural applications above $1150{ }^{\circ} \mathrm{C}$. Materials containing intermetallic phase(s)

*e-mail: brunobacci@yahoo.com.br with a refractory metal (RM - e.g. Mo, $\mathrm{Nb}$ or $\mathrm{Ti}$ ) and/or refractory alloy can overcome such temperature limit ${ }^{5,6}$. RM-Si-B systems present alloys with properties that are essential for these purposes, as high melting point, oxidation resistance and strength/mass ratio $^{7-10}$.

Nanostructured materials have received much attention because of their enhanced and unique properties. Some non-equilibrium processes have been developed, and ball milling turns to be the mostly used due to its simplicity, low cost and possibility of large-scale production. Ball milling also achieves good chemical and structural homogeneity, as well as control of the powder composition ${ }^{11-16}$. However, poor densification and undesirable grain growth may occur due to interparticle friction, surface contaminants and fine powders. Crystallization of amorphous Ti-Si compacts occurs mainly via increase in the density of nucleating crystallites, rather than growth of the existing crystals. The influence of annealing temperature on grain size in Ti-Si compacts is much higher than the dwell time and relatively independent of the powder mixture type ${ }^{17}$.

Recent experiments identified a $\mathrm{Ti}_{6} \mathrm{Si}_{2} \mathrm{~B}$ phase in $\mathrm{Ti}-\mathrm{Si}-\mathrm{B}$ alloys, which presents a small region of stability at $1250{ }^{\circ} \mathrm{C}^{18}$. Furthermore, two- and three-phase alloys with metallic (Ti) and intermetallic (e.g. $\mathrm{Ti}_{6} \mathrm{Si}_{2} \mathrm{~B}$ or $\mathrm{Ti}_{5} \mathrm{Si}_{3}$ ) matrices can be produced by powder metallurgy techniques ${ }^{19,20}$. However, strong sticking on the milling tools is verified when Ti-Si-B powders are processed in a planetary ball mill. 
Knowledge of the phases obtained after milling and sintering of Ti-Si-B powders has fundamental importance for better alloy design and processing control. Erroneous conclusions may be drawn if the physicochemical evolution of powders and compacts is not monitored. Synthesis study of two Ti-Si-B mixtures by high-energy ball milling (HEBM) and sintering is the principal objective of this investigation. Production of Ti-Si-B powders with high chemical homogeneity and yield is another goal of the current study. Then, some different milling conditions were adopted to attain these objectives. The present paper reports on preparation, phase transformations and properties of Ti-18Si-6B and Ti-7.5Si-22.5B at. (\%) powder mixtures and alloys using high-purity elemental powders as feedstock.

\section{Experimental Procedure}

High-purity Ti (99.9 wt. (\%), <150 mesh); B (99.5 wt. (\%), <120 mesh); and Si (99.999 wt. (\%), $<120$ mesh) Alpha Aesar powders were used for HEBM of Ti-18Si-6B and Ti-7.5Si-22.5B at. (\%) mixtures. HEBM was carried out under argon atmosphere in a Fritsch planetary ball mill using stainless steel vials and balls, as well as a ball-to-powder weight ratio of 10:1. The as-milled powders were weighted throughout the milling processes to verify their yield. Such powders were handled in a glove box under argon atmosphere to avoid reactions with air. Three milling routes (MR) were used to prepare the Ti-18Si-6B and Ti-7.5Si-22.5B at. (\%) mixtures. Such routes were chosen based on a study performed by Zoz et al. ${ }^{21}$ and previous experience from our researches. Table 1 summarizes the different parameters for such routes.

Some as-milled powders (MR1 and MR2) were uniaxially pressed under approx. $620 \mathrm{MPa}$ and a 5-minute dwell time. These green compacts were pressureless sintered at $1200{ }^{\circ} \mathrm{C}$ for 4 hours under argon atmosphere.

Ti-Si-B powders prepared with MR3 parameters were uniaxially pressed under $100 \mathrm{MPa}$ and a 60-second dwell time. These compacts were isostatically pressed under $300 \mathrm{MPa}$ and a 90-second dwell time. The green compacts were uniaxially hot-pressed under $900{ }^{\circ} \mathrm{C}, 30 \mathrm{MPa}$ and a 30-minute dwell time.

Sintered samples measured $10 \mathrm{~mm}$ in diameter and 2-5 $\mathrm{mm}$ in thickness. Table 2 relates the quantity of fabricated compacts and their constituent as-milled powders versus the three milling routes.

$\mathrm{X}$-ray diffraction (XRD) patterns were obtained at room temperature in a Seifert diffractometer $(\mathrm{CuK} \alpha$ radiation using Ni filter) at $40 \mathrm{kV}$ and $30 \mathrm{~mA}$. Such data were collected by the step counting method in the range $2 \theta$ of $20-80^{\circ}$ (step of $0.05^{\circ}$, and a counting time per step of 3 seconds).

Morphology and composition of the Ti-Si-B samples were characterized by scanning electron microscopy (SEM). Powdered materials were deposited on carbon adhesive tape fixed to specimen tabs prior to SEM measurements. Chemical analysis of the materials was performed by energy dispersive spectrometry (EDS). Hardness was measured using a Vickers microhardness device (Micromet 2004, Buehler) with 200-gf load.

Table 1. Parameters for the milling routes.

\begin{tabular}{|c|c|c|c|}
\hline & $\mathbf{1}^{\text {st }}$ Milling route (MR1) & $2^{\text {nd }}$ Milling route (MR2) & $3^{\text {rd }}$ Milling route (MR3) \\
\hline Milling conditions & $\begin{array}{l}\text { (1) Operation cycle - } 300 \text { rpm for } 4 \text { minutes } \\
\text { and } 200 \text { rpm for } 1 \text { minute (10 hours in this } \\
\text { condition); } \\
+ \\
\text { (2) Discharging cycle }-200 \text { rpm for } \\
4 \text { minutes and } 300 \text { rpm for } 1 \text { minute ( } 1 \text { hour } \\
\text { under this condition); } \\
+ \\
\text { (3) Uninterrupted milling (superhigh-energy } \\
\text { only for the Ti-7.5Si-22.5B powders } \\
\text { due to their more distinct sticking } \\
\text { mechanisms) - 300 rpm for } 10 \text { hours, } \\
\text { totalizing } 21 \text { hours for this mixture. }\end{array}$ & $\begin{array}{c}\text { Constant rotary } \\
\text { speed - } 200 \text { rpm with } \\
\text { interruption of } 15 \text { minutes } \\
\text { every } 1 \text { hour of milling }\end{array}$ & $\begin{array}{c}\text { Constant rotary } \\
\text { speed }-200 \mathrm{rpm} \text { with } \\
\text { interruption of } 10 \text { minutes } \\
\text { every } 10 \text { minutes of milling }\end{array}$ \\
\hline $\begin{array}{l}\text { Collection of samples } \\
\text { (hours) }\end{array}$ & $1,3,5,7,10,11,21^{*}$ & $1,5,30,60,100,200$ & $\begin{array}{c}1,10,30,60,80,120,150 \\
185^{* *}, 195^{*}\end{array}$ \\
\hline $\begin{array}{l}\text { Total collection } \\
\text { (hours) }\end{array}$ & $10,11,21^{*}$ & 200 & $\begin{array}{c}10,30,60,80,120,150 \\
185^{* *}, 195^{*}\end{array}$ \\
\hline Ball diameters & $19 \mathrm{~mm}$ & $19 \mathrm{~mm}$ & $\begin{array}{c}8 \text { balls of } 19 \mathrm{~mm} \text { and } 15 \text { balls } \\
\text { of } 12 \mathrm{~mm}\end{array}$ \\
\hline
\end{tabular}

*only Ti-7.5Si-22.5B mixture, **only Ti-18Si-6B mixture.

Table 2. Quantity of compacts and milling time.

\begin{tabular}{|c|c|c|c|}
\hline & $1^{\text {st }}$ Milling route (MR1) & $2^{\text {nd }}$ Milling route (MR2) & $3^{\text {rd }}$ Milling route $(\mathrm{MR3})$ \\
\hline Quantity of compacts & 2 (one of each alloy) & 2 (one of each alloy) & 4 (two of each alloy) \\
\hline $\begin{array}{l}\text { Milling time of the } \\
\text { sintered powders }\end{array}$ & 10 hours & 200 hours & $\begin{array}{c}60 \text { hours and a } 80 / 85 \text { hours mixture } \\
\text { (Ti-18Si-6B) and } 85 / 120 \text { hours mixture } \\
\text { and a 150/160/170 hours mixture } \\
\text { (Ti-7.5Si-22.5B) }\end{array}$ \\
\hline
\end{tabular}


Measurements of dry friction coefficient were accomplished in a ball-on-disk tribometer from CSM Instruments. Parameters used were: load of $1 \mathrm{~N}$ with a 3-mm diameter alumina ball as a counterpart material, linear speed of $5 \mathrm{~cm} / \mathrm{s}$ and track radius of $2 \mathrm{~mm}$. Disk volume loss and wear rate were calculated according to equations in the ASTM G-9922.

\section{Results and Discussion}

MR3 presents the best results for powder yield (Table 3) due to the collection procedures. Through this route, unlike MR1 and MR2, the overall powders that have not stuck were collected after every 10 hours milling (see Table 1). The final milling times of all routes exceed the mechanical alloying limits, which are characterized by thermal reactions that generate severe cold welding of the powders to the grinding tools. The silicon-rich mixtures have featured less cold welding than the Ti-7.5Si-22.5B ones, as demonstrated

Table 3. Powder yield.

\begin{tabular}{cccc}
\hline & MR1 (\%) & MR2 (\%) & MR3 (\%) \\
\hline Ti-7.5Si-22.5B & 8.3 & 8.6 & 32.7 \\
Ti-18Si-6B & 22.9 & 7.7 & 82.8 \\
\hline
\end{tabular}

by their higher yielding values. This behavior can also be observed on the grinding tools with the naked eye.

However, boron-rich powders presented slightly higher yielding values through MR2 than they did through the other routes. This is mostly as a result of the collection procedures, which have intermediary random removals for XRD and SEM analyses. Such removals were a big influence on the final yielding values for MR2, whereas the total powders that nave not stuck were only withdrawn after 200 hours milling and they were almost the same in this final collection. Powder yield of the silicon-rich mixture was sharply reduced after approximately 100 hours, however the other mixture suffers such reduction after around 2 hours.

Figure 1 shows XRD spectra of the as-milled Ti-Si-B powders processed under different conditions. All powder patterns of the present research contain a vertical line at $2 \theta=40.15^{\circ}$ that corresponds to the main peak of the standard $\alpha$-titanium. Despite differences in the milling parameters, similar intensity reductions of such peaks were detected after 1 hour milling. These results are in agreement with the SEM analyses (Figure 3, apud Fernandes et al. $(2005,2007))^{20,23}$, since there are significant chemical variations in the powder mixtures that justify such small deviations.

After 5 hours (MR1 and MR2) ${ }^{20}$ and 10 hours (MR3) ${ }^{23}$ milling, analysis through XRD on all Ti-Si-B powders has presented solely titanium peaks, suggesting that chemical

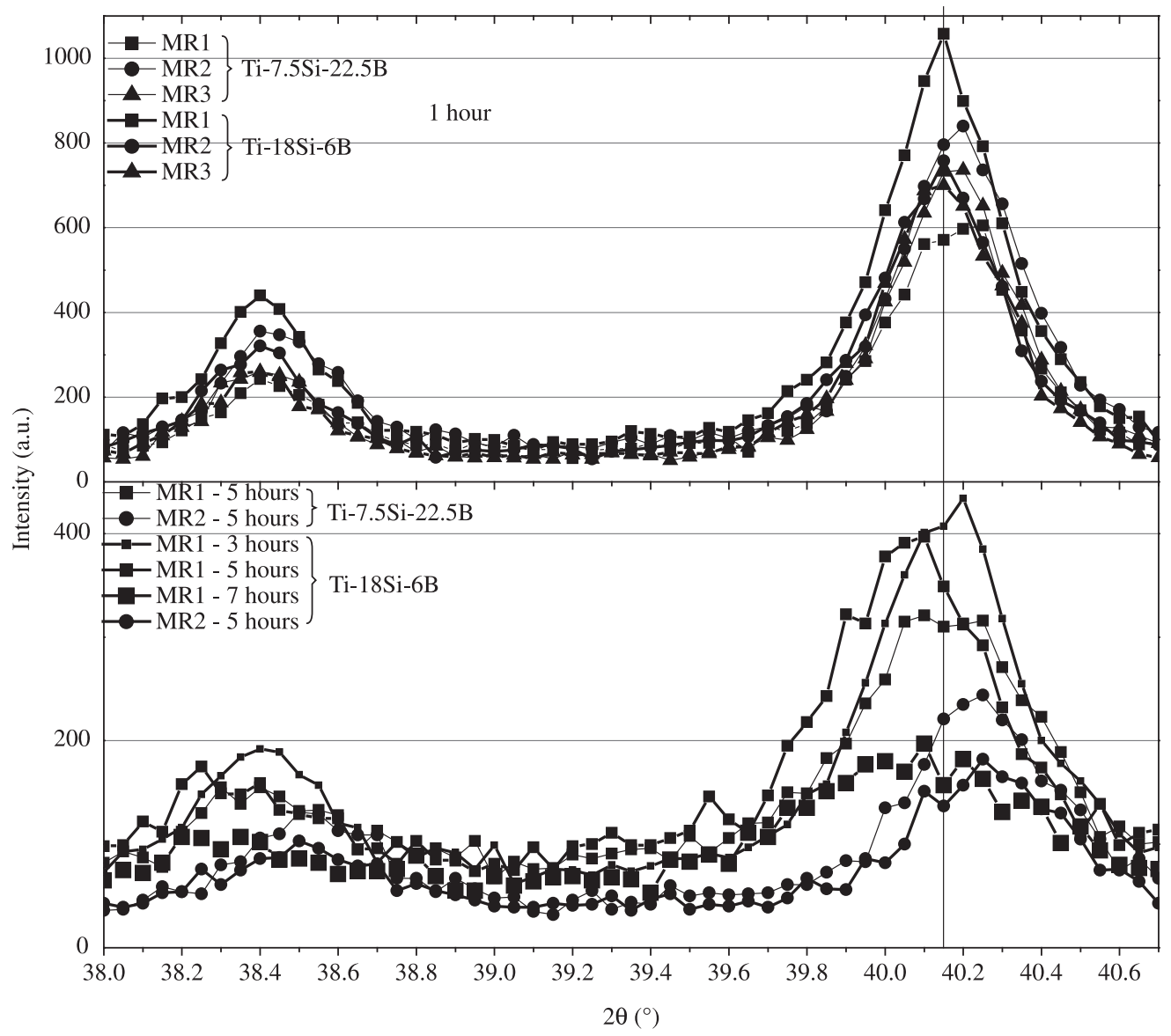

Figure 1. Comparison of the XRD region comprising the (011) and (002) Ti peaks for different compositions and conditions. 
and structural homogeneity processes were achieved ${ }^{24}$. Other plausible explanation for the $\mathrm{Si}$ and $\mathrm{B}$ peaks to disappear could be surface accumulation of titanium.

Average particle size has increased through intense cold welding among ductile particles (in higher proportion) after 5 hours (MR1 and MR2) and 10 hours (MR3) for all as-milled powders. Such effect and their irregular morphology can be observed on SEM micrographs ${ }^{20,23}$ (Figure 3), and size variation in particular is object to further examination (Figure 2). This cold welding phenomenon is named Critical Ball Milling (CBM) behavior, and in some cases, it exceeds the shear mechanism.

For the Ti-7.5Si-22.5B powders, particle size has increased less through MR2 than MR1. This could also account for the more pronounced reduction of XRD peaks on the earlier, as analysis has shown.

After 10 hours (MR1) both powders have presented a reduction in particle $\operatorname{size}^{20}$ (Figure 2), which is a behavior common to ductile-brittle mixtures as seen on literature ${ }^{24}$. Such reduction is caused by spot precipitation of hard intermetallic phases ${ }^{19}$ and work-hardening.

Reduction on particle size has also been observed for both mixtures through MR2 and MR3 after 30 hours (Figure 5). Titanium peaks of both mixtures gradually became broader and smaller (Figure 4). This could be interpreted as a combination of dissolution, disordering, smaller crystallites and particle size ${ }^{24}$. Particularly, the boron-rich mixture presents a more pronounced particle reduction after 30 hours (MR3) (Figure 2) due to exothermic reactions. Such reactions increase the temperature which in turn induces titanium recrystallization. However, the Ti-18Si-6B mixture presents smaller titanium peaks and rounded particles, which can be associated to an amorphous structure formation ${ }^{23}$.

After 11 hours (MR1) cold welding has intensified, consequently average particle size and XRD peaks of both mixtures have increased $(<500 \mu \mathrm{m})^{20}$. Ten hours later XRD peaks reduced slightly (Ti-7.5Si-22.5B mixture), most likely due to iron contamination.

Figure 6 shows the morphology of Ti-18Si-6B and Ti-7.5Si-22.5B powders milled for 60 hours (MR2). Particle size of the Ti-18Si-6B mixture suffers reduction, while that of the other mixture increases slightly. After 60 hours up to final milling times (MR2 and MR3), XRD results show broad halo patterns with minor variations which are similar to those seen on the lower section of Figure $4^{23}$.

Rounded aggregates are observed for both powder mixtures after 100 hours milling (Figure $7^{23}$ ). Such
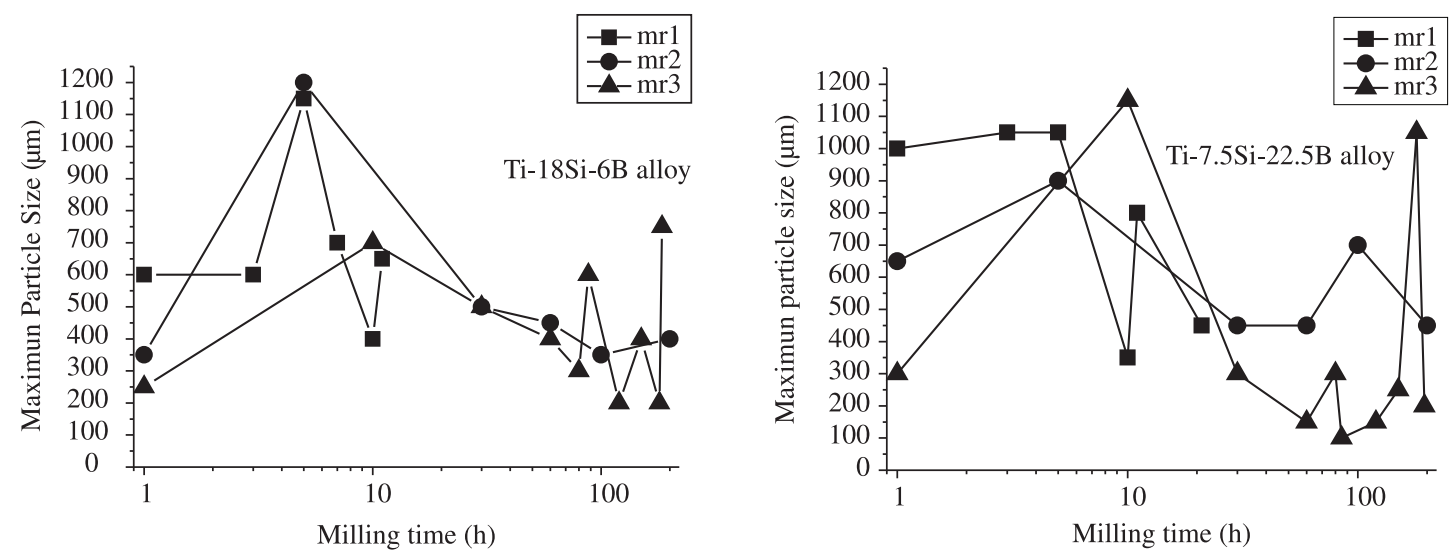

Figure 2. Maximum particle size versus milling time of Ti-Si-B powders.

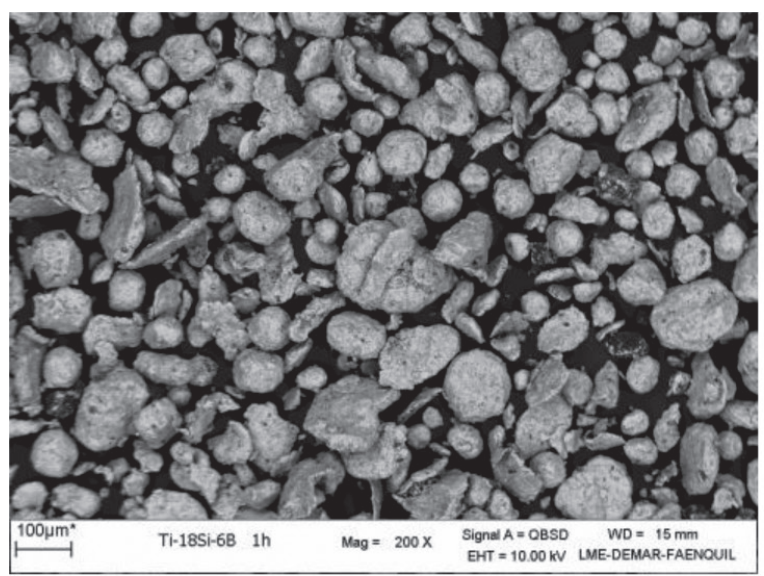

(a)

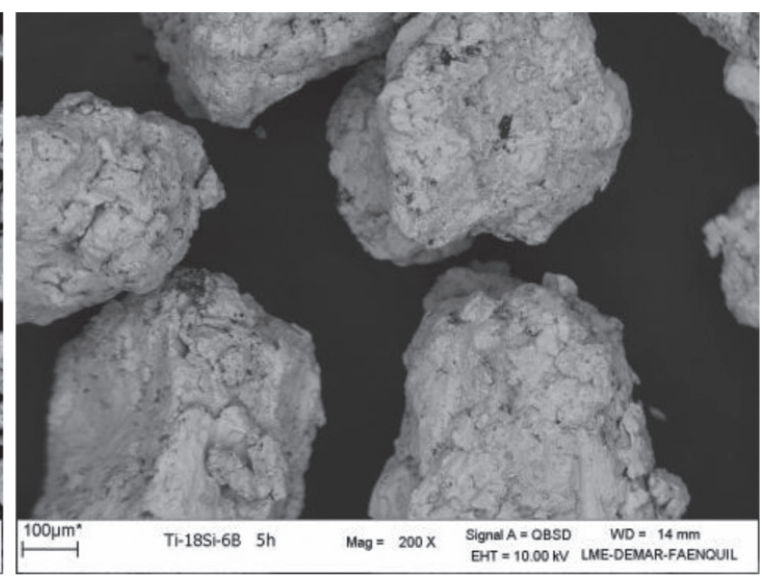

(b)

Figure 3. SEM images showing Ti-18Si-6B morphology for different milling times (MR2): (a) 1 hour and (b) 5 hours. Magnification - 200x. 
characteristics are related to the formation of amorphous structures ${ }^{24}$.

Figure 8 shows rounded and irregular morphologies of as-milled Ti-7.5Si-22.5B particles after 200 hours. Such morphologies are visualized in Ti-18Si-6B and Ti-7.5Si-22.5B powders milled for 185 to 200 hours (MR2 and MR3 $)^{23}$, with heterogeneous size distribution $(<400 \mu \mathrm{m})$ and some anomalous particles $(>800 \mu \mathrm{m})$.
Synthesis of pure titanium by ball milling (under argon or air) has been performed by different authors ${ }^{11,25,26}$, and they have reported formation of a FCC phase after milling for a few hours. Presence of boron acting as an $\alpha$ stabilizer explains the lack of such a formation in our research.

EDS analyses of the particles show a maximum 4.0 at. $(\%)$ of metallic contamination $(\mathrm{Fe}, \mathrm{Ni}, \mathrm{Cr})$, which is much less than that encountered in titania powders



Figure 4. Comparison of the XRD region comprising the (011) and (002) Ti peaks for different compositions and conditions.



(a)



(b)

Figure 5. SEM images showing as-milled powders after 30 hours (MR2): (a) Ti-18Si-6B and (b) Ti-7.5Si-22.5B. Magnification - 200x. 


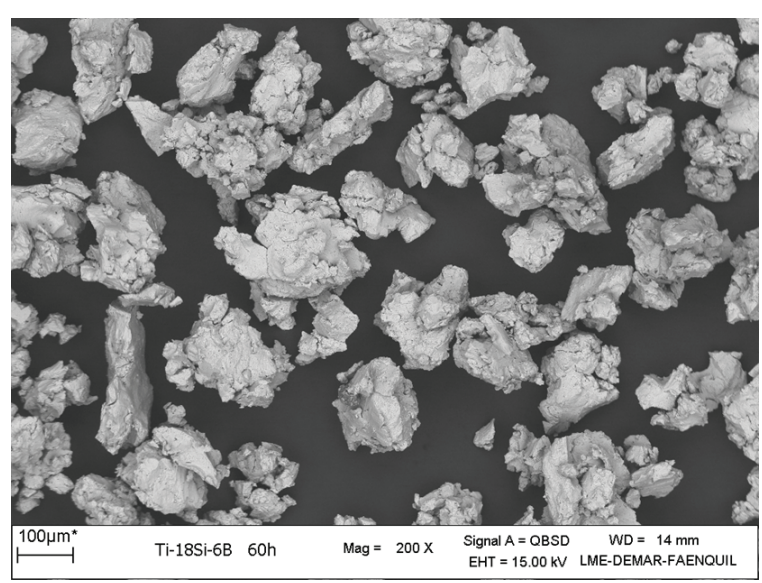

(a)

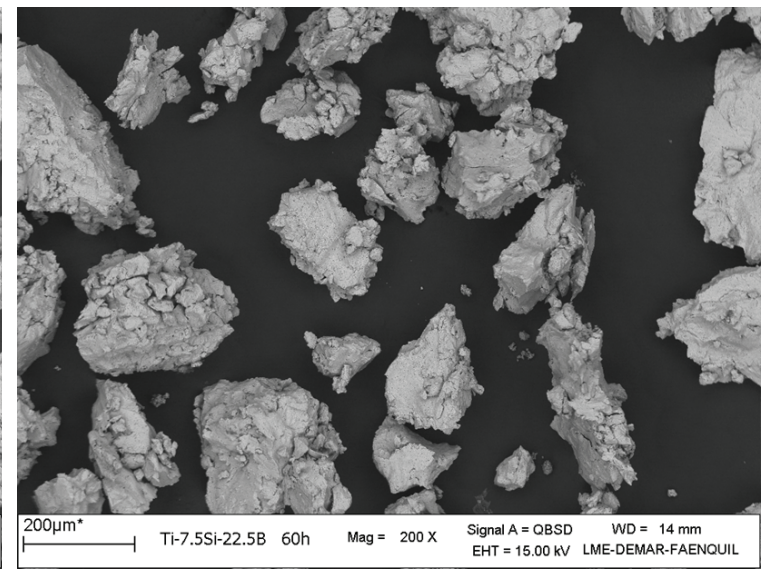

(b)

Figure 6. SEM images showing the morphology of as-milled powders after 60 hours (MR2): (a) Ti-18Si-6B and (b) Ti-7.5Si-22.5B. Magnification - 200x.

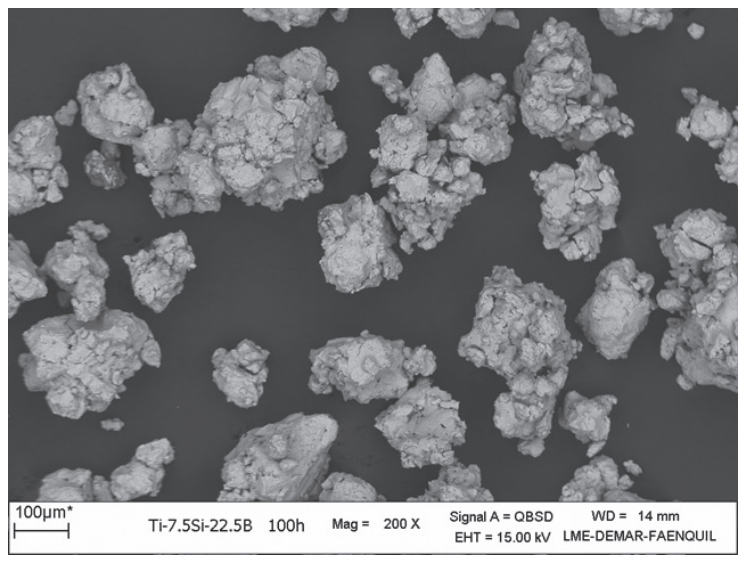

Figure 7. SEM image showing the morphology of Ti-7.5Si-22.5B powders after 100 hours milling (MR2). Magnification - 200x.

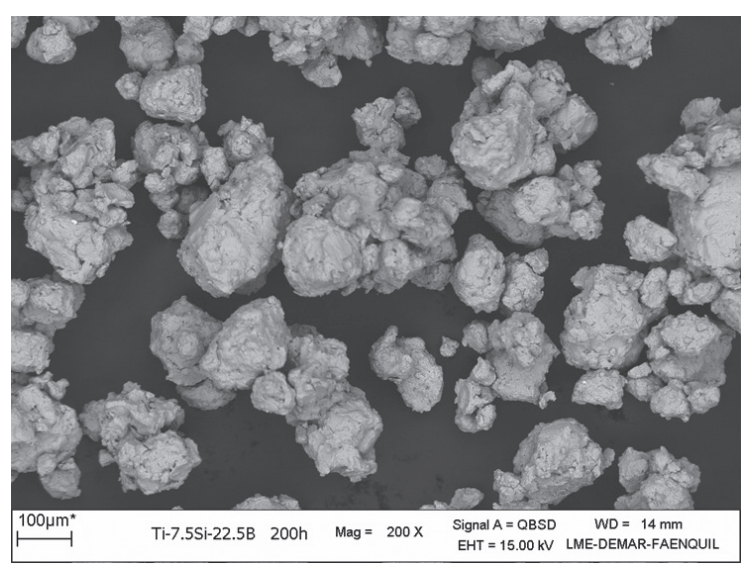

Figure 8. SEM image showing the morphology of Ti-7.5Si-22.5B powders after for 200 hours milling (MR2). Magnification - 200x.

(22.0 at. $(\%))^{27}$. This difference can be attributed to the higher hardness of the titania powders.

Mechanically alloyed polycrystalline aggregates of $400-\mu \mathrm{m}$ maximum diameter were formed after 10 hours using the MR1 parameters ${ }^{20}$. Unlike the Ti-18Si-6B powders, finer particles $(<50 \mu \mathrm{m})$ are observed in the boron-rich mixture. XRD patterns and SEM images reveal that the $\alpha-\mathrm{Ti}_{1}, \mathrm{Ti}_{6} \mathrm{Si}_{2} \mathrm{~B}, \mathrm{Ti}_{5} \mathrm{Si}_{3}$ and $\mathrm{TiB}$ phases make up a major part of both alloys produced by sintering of these as-milled powders ${ }^{20}$. The presence of regions with high silicon content (23.5-26.3 at. (\%) and 33.1-37.2 at. (\%)) was detected by EDS analyses, which are associated with $\mathrm{Ti}_{6} \mathrm{Si}_{2} \mathrm{~B}$ and $\mathrm{Ti}_{5} \mathrm{Si}_{3}$ phases, respectively. Furthermore, an iron contamination of about 4.0 at. (\%) and 10.0 at. (\%) was detected in the Ti-18Si-6B and Ti-7.5Si-22.5B alloys, respectively. Such element was located in brighter regions $\left(\mathrm{Ti}_{\mathrm{ss}}\right.$, i.e. titanium solid solution) and the higher content verified in the boron-rich mixture must be associated to its more pronounced $\mathrm{CBM}$ behavior. The difference in average phase size between them may be related to $\mathrm{TiB}_{2}$ nanoprecipitations. Such precipitates are barriers for diffusion and as such, they are responsible for delay on grain growth.

Figure 9 displays XRD results of the Ti-18Si-6B and Ti-7.5Si-22.5B alloys (MR2) obtained after the same pressureless sintering at $1200{ }^{\circ} \mathrm{C}$ for 4 hours. All aforementioned phases have also been identified in these XRD patterns and in the SEM micrographs (Figure 10).

EDS analyses show silicon content of 22.7-27.5 at. (\%) and 32.6-37.1 at. (\%) in specific areas, which are the same $\mathrm{Ti}_{6} \mathrm{Si}_{2} \mathrm{~B}$ and $\mathrm{Ti}_{5} \mathrm{Si}_{3}$ phases mentioned earlier. Iron content up to 4.0 at. $(\%)$ is accumulated to form $\mathrm{Ti}_{\mathrm{ss}}$ regions. Titanium dissolves a small amount of iron $(<1.0$ at. $(\%))$ according to the $\mathrm{Fe}$-Ti phase diagram ${ }^{28}$, hence larger amounts may contribute to FeTi phase formation. However, identification of such phase is very difficult by the characterization techniques used in the present work. Fine structures resulting from sintering and the low content of FeTi phase must be characterized by more suitable techniques. Reduced particle size and high iron contamination of the as-milled Ti-7.5Si-22.5B powders (MR1) must be the reasons for the finer phase size $(<1 \mu \mathrm{m})$ observed after their sintering. The other three microstructures present phase size up to $20 \mu \mathrm{m}$.

After hot pressing $\left(900{ }^{\circ} \mathrm{C} / 30 \mathrm{MPa} / 30 \mathrm{~min}\right), \mathrm{XRD}$ patterns and SEM images of Ti-Si-B alloys ${ }^{23}$ also reveal that the $\mathrm{Ti}, \mathrm{Ti}_{6} \mathrm{Si}_{2} \mathrm{~B}, \mathrm{Ti}_{5} \mathrm{Si}_{3}$ and $\mathrm{TiB}$ phases represent a majority of the microstructures. EDS spot analysis detected iron 
content up to 6.0 at. (\%) and chromium/nickel content up to 2.0 at. (\%), which is a result of contamination picked up from the grinding tools.

SEM images of the Ti-7.5Si-22.5B alloy show regions with huge grains, probably due to existing particles where the dissolution process has not been completed. Such particles derive from preferential cold welding during milling. When comparing Ti-18Si-6B samples, a finer

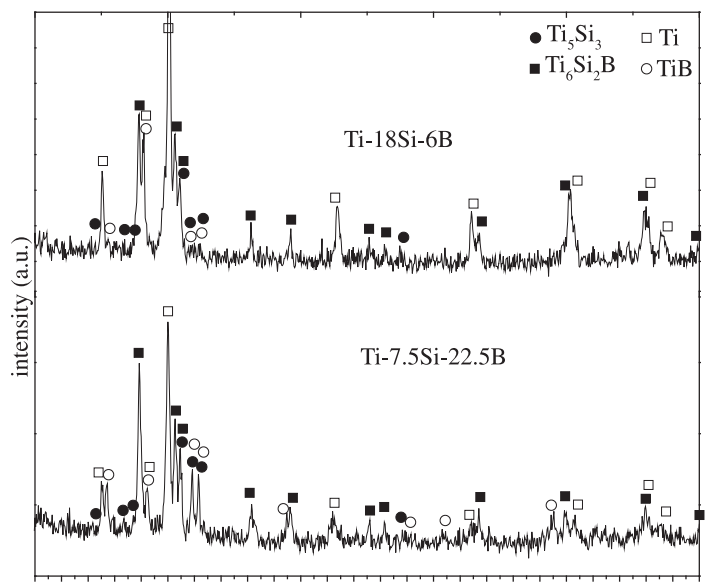

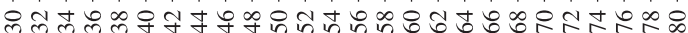

$2 \theta\left({ }^{\circ}\right)$

Figure 9. X-ray diffractograms of Ti-18Si-6B and Ti-7.5Si-22.5B alloys (MR2) produced by pressureless sintering at $1200{ }^{\circ} \mathrm{C}$ for 4 hours.

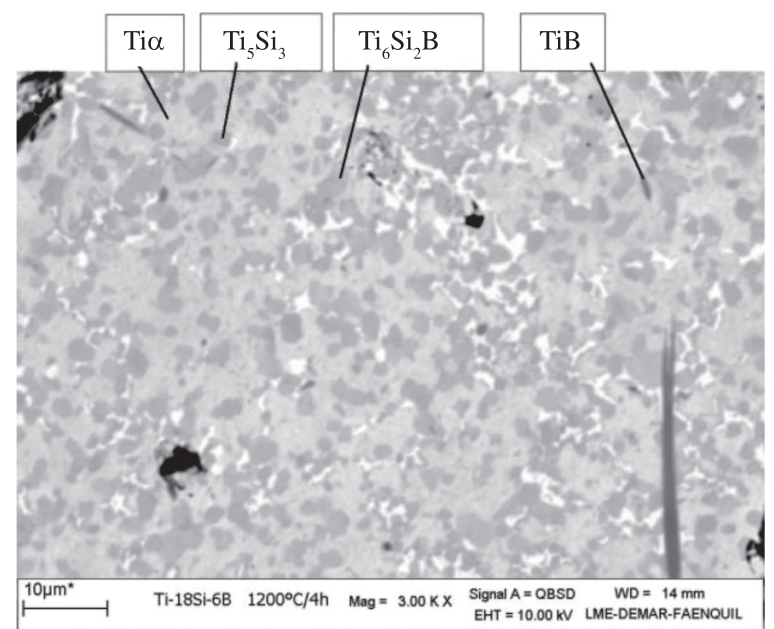

(a) phase size has been observed in one of them. The longer milling time of this sample could be the reason behind such variation, which can be verified with a comparison of their XRD halos. Higher phase sizes should be generated in the pressureless sintered samples, however such sizes are similar to the hot-pressed samples. Features like these are important and should be investigated further on future researches, but are not the objective of this study.

According to the Ti-Si-B diagram ${ }^{18}$, Ti-18Si-6B should have 30.3 at. (\%) of Ti, 20.7 at. (\%) of $\mathrm{Ti}_{5} \mathrm{Si}_{3}$ and 49.0 at. (\%) of $\mathrm{Ti}_{6} \mathrm{Si}_{2} \mathrm{~B}$; and $\mathrm{Ti}-7.5 \mathrm{Si}-22.5 \mathrm{~B}$ should have 30.4 at. (\%) of $\mathrm{Ti}, 36.4$ at. (\%) of $\mathrm{TiB}$ and 33.2 at. (\%) of $\mathrm{Ti}_{6} \mathrm{Si}_{2} \mathrm{~B}$. The actual contents in the alloys produced here have been influenced by contamination and processing methods. As such, new phases have been formed and determining their exact quantity would present a much more complex endeavor. Further studies using both Rietveld and image analyses can be performed to accurately verify such contents.

Average hardness values of 676 and $946 \mathrm{HV}$ were measured for the Ti-18Si-6B and the Ti-7.5Si-22.5B samples (MR2), respectively (Table 4). These values are consistent with their structures (less TiB in the former alloy). The hot-pressed alloys have suffered an increment of some HV tens when compared to the sintered alloys, which must be attributed to their higher densification.

Milling effects can be seen in the density measurements (Table 5) of the hot-pressed samples. Higher density values of the compacts produced from as-milled powders cannot be solely related to an improvement on densification due to ball milling. Incorporation of heavy atoms ( $\mathrm{Fe}, \mathrm{Cr}$ and $\mathrm{Ni}$ ) must have played a role particularly on this outcome. The

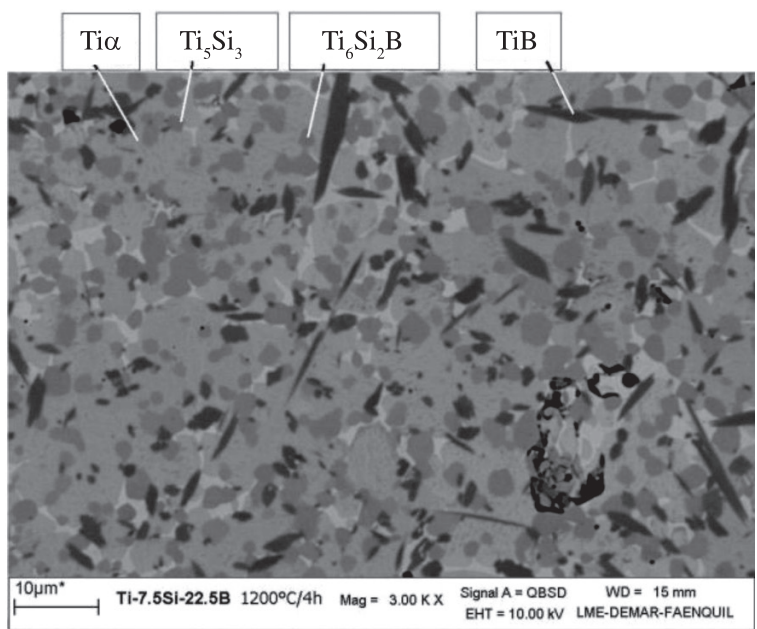

(b)

Figure 10. SEM images of: (a) Ti-18Si-6B and (b) Ti-7.5Si-22.5B alloys (MR2) produced by pressureless sintering at $1200^{\circ} \mathrm{C}$ for 4 hours. Magnification - 3000x.

Table 4. Hardness of the Ti-Si-B samples (HV or kgf.mm²).

\begin{tabular}{ccccc}
\hline \multirow{2}{*}{ Alloy } & \multirow{2}{*}{ MR1 } & MR2 & \multicolumn{2}{c}{ MR3 } \\
\cline { 3 - 5 } & & & $\mathbf{6 0}$ hours & $\mathbf{8 0 / 8 5}$ hours \\
\hline Ti-18Si-6B & $730.5 \pm 63.3$ & $676.5 \pm 63.3$ & $778.4 \pm 47.1$ & $772.5 \pm 14.4$ \\
& & & $\mathbf{8 5 / 1 2 0}$ hours & $\mathbf{1 5 0 / 1 6 0 / 1 7 0 ~ h o u r s ~}$ \\
Ti-7.5Si-22.5B & - & $946.4 \pm 189.9$ & $1094.5 \pm 104.4$ & $1063.2 \pm 11.6$ \\
\hline
\end{tabular}




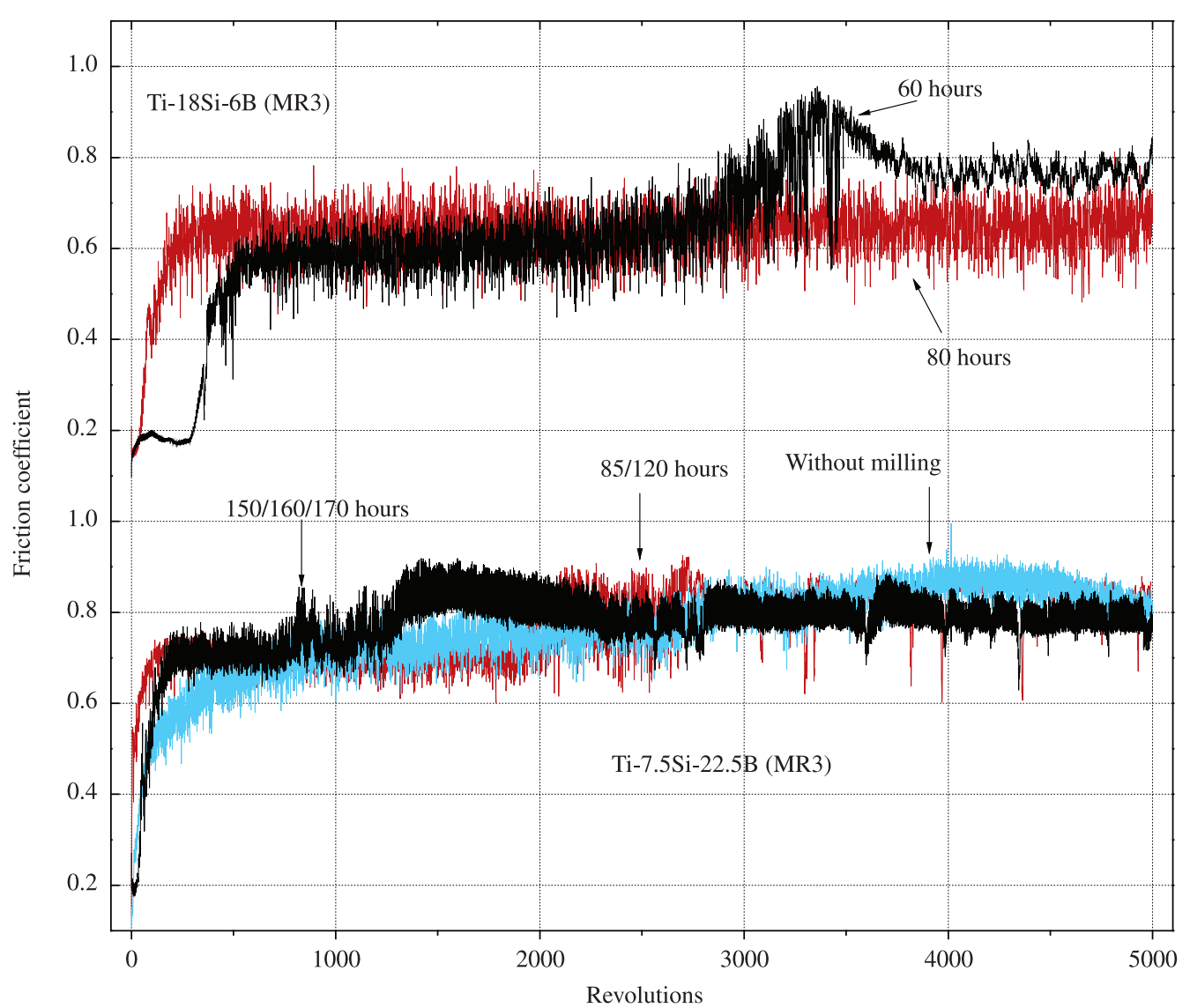

Figure 11. Friction coefficients of hot-pressed Ti-18Si-6B and Ti-7.5Si-22.5B alloys.

Table 5. Density of the Ti-Si-B samples obtained by hot pressing $\left(\mathrm{g} . \mathrm{cm}^{-3}\right)$.

\begin{tabular}{|c|c|c|c|}
\hline \multirow{2}{*}{ Alloy } & \multirow{2}{*}{$\begin{array}{l}\text { Without } \\
\text { milling }\end{array}$} & \multicolumn{2}{|r|}{ MR3 } \\
\hline & & 60 hours & $80 / 85$ hours \\
\hline \multirow[t]{2}{*}{ Ti-18Si-6B } & - & 4.3 & 4.3 \\
\hline & & $85 / 120$ hours & $150 / 160 / 170$ hours \\
\hline Ti-7.5Si-22.5B & 3.9 & 4.4 & 4.2 \\
\hline
\end{tabular}

Table 6. Wear rate of the Ti-Si-B samples obtained by hot pressing $\left(\mathrm{mm} 3 . \mathrm{Nm}^{-1}\right)$.

\begin{tabular}{cccc}
\hline \multirow{2}{*}{ Alloy } & \multirow{2}{*}{$\begin{array}{c}\text { Without } \\
\text { milling }\end{array}$} & \multicolumn{2}{c}{ MR3 } \\
\cline { 3 - 4 } & & $\mathbf{6 0}$ hours & $\mathbf{8 0 / 8 5}$ hours \\
\hline Ti-18Si-6B & - & 0.10 & 0.10 \\
& & $\mathbf{8 5 / 1 2 0}$ hours & $\mathbf{1 5 0 / 1 6 0 / 1 7 0 ~ h o u r s ~}$ \\
Ti-7.5Si-22.5B & 0.14 & 0.11 & 0.13 \\
\hline
\end{tabular}

slight differences of density among the compacts produced from as-milled powders can be attributed to the different morphologies, compositions and sizes of such powders.

For the compacts of which powders have undergone milling, the higher densification obtained helps improving their tribological properties as shown by friction tests
(Table 6 and Figure 11). Even though friction coefficients have not been reduced, wear rates have shown some improvement.

\section{Conclusions}

This study has found that cold welding among ductile particles has retained its relevance despite the addition of brittle components. As such, all milling routes have presented a reduction on powder yield after few hours.

Higher powder yield has been obtained through MR3, which must be attributed mainly to the collection procedures adopted. Another likely influence could be the lower temperatures, more frequent interruptions or lower rotary speed employed under this route. Furthermore, recovery and recrystallization may occur because of higher temperatures. Consequently, they have also reduced hardening rates and increased powder sticking to the grinding tools.

Metastable structures (extended solid solution and amorphous phases) have been formed during milling of the Ti-18Si-6B and Ti-7.5Si-22.5B powder mixtures for all milling routes. EDS analyses have allowed identification of the $\mathrm{Ti}+\mathrm{Ti}_{6} \mathrm{Si}_{2} \mathrm{~B}+\mathrm{Ti}_{5} \mathrm{Si}_{3}+\mathrm{TiB}$ phases as the majority of all sintered alloys produced in this work. Such analyses also indicate iron contamination during milling accumulates in $\mathrm{Ti}_{\text {ss }}$ regions. 
Fine and uniformly dispersed precipitates of $\mathrm{Ti}_{6} \mathrm{Si}_{2} \mathrm{~B}$, $\mathrm{Ti}_{5} \mathrm{Si}_{3}$ and $\mathrm{TiB}$ are formed in $\mathrm{Ti}-18 \mathrm{Si}-6 \mathrm{~B}$ and $\mathrm{Ti}-7.5 \mathrm{Si}-22.5 \mathrm{~B}$ powder alloys. They are smaller than those produced by arc melting, which may improve mechanical properties of these compositions. High hardness values have been verified on hot-pressed samples. Densification and tribological properties were slightly improved due to high-energy ball milling.

The data presented by this work in these conditions is relevant to various applications, such as modeling and providing a comprehensive comparison of different materials and conditions (in this case, high-purity powders milled on SS vessels and balls, and under argon atmosphere). Notwithstanding, the parameters chosen also represent a significant reduction on costs related to milling processes (in comparison to titanium or other).

\section{References}

1. Clarke MT, Lee PTH, Arora A and Villar RN. Levels of Metal Ions after Small- and Large-Diameter Metal-on-Metal Hip Arthroplasty. The Journal of \& Joint Surgery British. 2003; 85B(6):913-917.

2. Reclaru L, Eschler P-Y, Lerf R and Blatter A. Electrochemical Corrosion and Metal Ion Release from Co-Cr-Mo Prosthesis with Titanium Plasma Spray Coating. Biomaterials. 2005; 26:47474756. PMid:15763254. http://dx.doi.org/10.1016/j. biomaterials.2005.01.004

3. Kato MKN, Onari E, Arisawa EAL, Silva NSD and Ramos AS. Osseointegration features of orthopedic Ti-10Si-5B implants. Materials Science \& Engineering C. 2009; 29:980-986. http:// dx.doi.org/10.1016/j.msec.2008.08.022

4. Jha AK, Diwakar V, Pant B and Sreekumar K. Failure Analysis of a Ti-6Al-4V Gas Bottle. Engineering Failure Analysis. 2006; 13:843-856. http://dx.doi.org/10.1016/j. engfailanal.2005.02.011

5. Frommeyer G, Rosenkranz R and Lüdecke C. Microstructure and Properties of the Refractory Intermetallic $\mathrm{Ti}_{5} \mathrm{Si}_{3}$ Compound and the Undirectionally Solidified Eutectic $\mathrm{Ti}_{-} \mathrm{Ti}_{5} \mathrm{Si}_{3}$. Zeitschrift für Metallkunde. 1990; 81:307-313.

6. Gorsse S, Chaminade JP and Le Petitcorps Y. In Situ Preparation of Titanium Base Composites Reinforced by TiB Single Crystals using Powder Metallurgy Technique. Composites Part A. 1998; 29:1229-1234.

7. Nunes CA, Sakidja R, Dong $Z$ and Perepezko JH. Liquidus Projection for the Mo-Rich Portion of the Mo-Si-B Ternary System. Intermetallics. 2000; 8:327-337. http://dx.doi. org/10.1016/S0966-9795(99)00088-6

8. Behrani V, Thom AJ, Kramer MJ and Akinc M. Microstructure and Oxidation Behavior of the Nb-Mo-Si-B Alloys. Intermetallics. 2006; 14:24-32. http://dx.doi.org/10.1016/j. intermet.2005.03.007

9. Yang Y, Chang YA and Tan L. Thermodynamic Modeling and Experimental Investigation of the Ti-Rich Corner of the Ti-Si-B System. Intermetallics. 2005; 13:1110-1115. http://dx.doi. org/10.1016/j.intermet.2005.02.001

10. Ramos ECT, Silva G, Ramos AS, Nunes CA and Baptista CARP. Microstructure and Oxidation Behavior of Ti-Si-B Alloys. Materials Science \& Engineering A. 2003; 363(1-2):297-306. http://dx.doi.org/10.1016/S0921-5093(03)00650-6

\section{Acknowledgements}

The authors gratefully acknowledge the support from Fundação de Amparo à Pesquisa do Estado de São Paulo (FAPESP), Conselho Nacional de Pesquisa e Desenvolvimento $(C N P q)$, Instituto Tecnológico de Aeronáutica (ITA), Instituto Nacional de Pesquisas Espaciais (INPE), Universidade do Vale do Paraíba (UNIVAP) and Instituto de Aeronáutica e Espaço (IAE). The authors also would like to thank Geraldo do Prado for his help with metallographic operations; Alice Ueda for her inestimable advices concerning chemistry; João Batista Rodrigues and Claudemir Patuci for the hardness measurements; and several co-workers at ITA, INPE, IAE and USP.

11. Phasha MJ, Bolokang AS and Ngoepe PE. Solid-State Transformation in Nanocrystalline Ti Induced by Ball Milling. Materials Letters. 2010; 64:1215-1218. http://dx.doi. org/10.1016/j.matlet.2010.02.054

12. Gomari S and Sharafi S. Microstructural Characterization of Nanocrystalline Chromium Carbides Synthesized by High Energy Ball Milling. Journal of Alloys and Compounds. 2010; 490:26-30. http://dx.doi.org/10.1016/j. jallcom.2009.10.041

13. Bhattacharya P, Bellon P, Averback RS and Hales SJ. Nanocrystalline TiAl Powders Synthesized by High-Energy Ball Milling: Effects of Milling Parameters on Yield and Contamination. Journal of Alloys and Compounds. 2004; 368:187-196. http://dx.doi.org/10.1016/j. jallcom.2003.08.079

14. Lohse BH, Calka A and Wexler D. Synthesis of TiC by Controlled Ball Milling of Titanium and Carbon. Journal of Materials Science. 2007; 42:669-675. http://dx.doi. org/10.1007/s10853-006-0291-5

15. Kumaran S, Sasikumar T, Arockiakumar R and Rao TS. Nanostructured Titanium Aluminides Prepared by Mechanical Alloying and Subsequent Thermal Treatment. Powder Technology. 2008; 185:124-130. http://dx.doi.org/10.1016/j. powtec.2007.10.006

16. Zhang Z, Sandström R, Frisk $K$ and Salwén A. Characterization of Intermetallic Fe-Mn-Si Powders Produced by Casting and Mechanical Ball Milling. Powder Technology. 2003; 137:139-147. http://dx.doi.org/10.1016/j. powtec.2003.08.058

17. Counihan PJ, Crawford A and Thadhani NN. Influence of Dynamic Densification on Nanostructure Formation in $\mathrm{Ti}_{5} \mathrm{Si}_{3}$ Intermetallic Alloy and its Bulk Properties. Materials Science \& Engineering A. 1999; 267:26-35. http://dx.doi.org/10.1016/ S0921-5093(99)00056-8

18. Ramos AS, Nunes CA, Rodrigues G, Suzuki PA, Coelho GC, Grytsiv A et al. $\mathrm{Ti}_{6} \mathrm{Si}_{2} \mathrm{~B}$, a New Ternary Phase in the Ti-Si-B System. Intermetallics. 2004; 12(5):487-491. http://dx.doi. org/10.1016/j.intermet.2004.01.001

19. Silva AN, Silva G, Ramos AS, Paschoal AL, Ramos ECT and Filgueira M. Preparation of $\mathrm{Ti}+\mathrm{Ti}_{6} \mathrm{Si}_{2} \mathrm{~B}$ Powders by High-Energy Ball Milling and Subsequent Heat Treatment. Intermetallics. 2006; 14:585-591. http://dx.doi.org/10.1016/j. intermet.2005.08.005 
20. Fernandes BB, Ramos AS and Suzuki PA. Preparation of $\mathrm{Ti}+\mathrm{Ti}_{6} \mathrm{Si}_{2} \mathrm{~B}+\mathrm{Ti}_{5} \mathrm{Si}_{3}$ and $\mathrm{Ti}+\mathrm{Ti}_{6} \mathrm{Si}_{2} \mathrm{~B}+\mathrm{TiB}$ Powders by High-Energy Ball Milling and Subsequent Heat Treatment. Journal of Metastable and Nanocrystalline Materials. 2005; 24-25:467-471. http://dx.doi.org/10.4028/www.scientific.net/ JMNM.24-25.467

21. Zoz H, Ernst D, Weiss H, Magini M and Powell C. Mechanical Alloying of Ti-24Al-11Nb (at.\%) using the Simoloyer. Metall. 1996; 50:575-579.

22. American Society for Testing and Materials - ASTM. G-99 Standard Test Method for Wear Testing with a Pin-on-Disk Apparatus. ASTM Standards; 2000.

23. Fernandes BB, Ramos AS, Moura Neto C, Melo FCL and Fernandes PB. Structural Characterization of Ti-18Si-6B and Ti-7.5Si-22.5B Alloys Processed by High-Energy Ball Milling and Hot Pressing. Tecnologia em Metalurgia e Materiais. 2007; 4(2):56-62. (in portuguese). http://dx.doi. org/10.4322/tmm.00402011
24. Suryanarayana C. Mechanical Alloying and Milling. Progress in Materials Science. 2001; 46:1-184. http://dx.doi. org/10.1016/S0079-6425(99)00010-9

25. Chatterjee P and Sen Gupta SP. An X-Ray Diffraction Study of Nanocrystalline Titanium Prepared by High-Energy Vibrational Ball Milling. Applied Surface Science. 2001; 182:372-376. http://dx.doi.org/10.1016/S0169-4332(01)00451-2

26. Lu CJ, Zhang J and Li ZQ. Structural Evolution of Titanium Powder During Ball Milling in Different Atmospheres. Journal of Alloys and Compounds. 2004; 381:278-283. http://dx.doi. org/10.1016/j.jallcom.2004.03.130

27. Hara KO, Yamasue E, Okumura $\mathrm{H}$ and Ishihara KN. Formation of Metastable Phases by High-Energy Ball Milling in the Ti-O System. Journal of Physics: Conference Series. 2009; 144:012021. http://dx.doi.org/10.1088/1742-65 96/144/1/012021

28. Murray JL. ASM Handbook - Alloy Phase Diagrams. Materials Park. 1992; 3:205. 